\title{
Estudo histológico da penetração do estilete da Pérola da Terra Eurhizococcus brasiliensis (Wille, 1922) (Hemiptera:Margarodidae) nas Raízes de Videira
}

\author{
Marcelina Mezzomo Debiasi \\ Universidade do Oeste de Santa Catarina (UNOESC) - Campus Joaçaba \\ (marcelina.debiasi@unoesc.edu.br)
}

Márcia Bündchen

Instituto Federal de Educação, Ciência e Tecnologia do Rio Grande do Sul (IFRS)

Campus Porto Alegre

(marcia.bundchen@poa.ifrs.edu.br)

\begin{abstract}
Katiane Paula Bagatini
Universidade do Oeste de Santa Catarina (UNOESC) - Campus Joaçaba

(katiane.bagatini@unoesc.edu.br)
\end{abstract}

Edegar Luiz Peruzzo

Empresa de Pesquisa Agropecuária e Extensão Rural de Santa Catarina (EPAGRI)

(peruzzo@epagri.sc.gov.br)

Fernanda Maurer D'Agostini

Universidade do Oeste de Santa Catarina (UNOESC) - Campus Joaçaba

(fernanda.dagostini@unoesc.edu.br)

Resumo: Eurhizococcus brasiliensis (Wille, 1922), a pérola da terra, é considerada a principal praga da videira no sul do Brasil e existe pouca informação sobre as interações inseto-planta. O objetivo deste estudo foi verificar o mecanismo de penetração de $E$. brasiliensis nas raízes de Vitis vinifera através de cortes histológicos. Amostras de 250 raízes de $V$. vinifera infestadas por $E$. brasiliensis foram coletadas e fixadas em FAA70 e armazenadas em etanol $70 \%$; Após a fixação das raízes infestadas, os segmentos foram desidratados, emblocados em parafina, seccionados e corados para a preparação de lâminas histológicas permanentes. As lâminas foram analisadas em microscópio de luz e os dados obtidos do estudo anatômico revelaram que o estilete de $E$. brasiliensis quando introduzido nos tecidos radiculares rompe as células e aproxima-se do xilema. A penetração do estilete forma um canal com as margens mais claras e irregulares atingindo até $650 \mu \mathrm{m}$ no interior dos tecidos da raiz.

Palavras-chave: Interação inseto-planta; Histologia da raiz; Vitis vinifera. 


\author{
Histological study of penetration of the brazilian ground pearl stylet \\ eurhizococcus brasiliensis (wille, 1922) (hemiptera: margarodidae) in Raízes de
} Videira

\begin{abstract}
Eurhizococcus brasiliensis (Wille, 1922), the Brazilian ground pearl, is considered the main vine pest in Southern Brazil and there is few information about the insect-plant interactions. The aim of this study was to verify the penetration mechanism of the E. brasiliensis in the roots of Vitis vinifera through histological cuts. Samples from $250 \mathrm{~V}$. vinifera roots infested by E. brasiliensis were collected and were fixated at $\mathrm{FAA}_{70}$ and stored in ethanol $70 \%$; then, root segments were dehydrated, molded in paraffin, sectioned and staining to prepare the permanent histological slides. The slides were analyzed under a light microscope and the obtained data from the anatomical studies revealed that the $E$. brasiliensis stylet when introduced in the root tissues, breaks the cells and reaches to the xylem. The root penetration of the stylet forms a track with clearer and more irregular margins reaching up to $650 \mu \mathrm{m}$ inside the root tissues.
\end{abstract}

Keywords: Insect-plant interaction; Root histology; Vitis vinifera.

\title{
INTRODUÇÃO
}

Eurhizococcus brasiliensis (Wille, 1922) Hemiptera, popularmente conhecida como "pérola da terra" ou "margarodes" é uma espécie de cochonilha neotropical endêmica do Brasil e encontrada principalmente na região Sul (BOTTON, 2010a; EFROM et al., 2012). É um parasita subterrâneo que se alimenta nas raízes de cerca de 70 espécies de plantas, incluindo videiras, cana-de-açúcar, palmeiras, algodão e diversas outras, causando assim sérios danos nestas culturas (FOLDI, 2005). As consequências da infestação de E. brasiliensis na produtividade da cultura de Vitis sp. têm maior impacto econômico em decorrência do papel da vitivinicultura na sustentabilidade econômica das pequenas propriedades rurais do sul do Brasil (MELLO, 2012).

$\mathrm{Na}$ literatura as hipóteses para o declínio e morte das plantas de videira, associadas à infestação pela cochonilha incluem: sucção contínua da seiva floemática; bloqueio da translocação de fotossimilados; toxicidade injetada pelo aparelho bucal e infecções secundárias, por microorganismos. Segundo Panizzi e Noal (1971) e Foldi (2005), o definhamento progressivo do parreiral pode ser devido à sucção contínua de seiva, resultando na redução da produção e consequente morte das plantas. Zart et al. (2014) constataram que a evolução dos sintomas foliares associados ao definhamento da planta está relacionada com uma redução na atividade fotossintética e com o acúmulo de amido nas folhas das plantas 
infestadas, sugerindo que decorram do bloqueio no transporte de fotoassimilados das folhas. Outra interpretação acerca dos sintomas indica que a saliva injetada pela cochonilha nos tecidos vegetais é tóxica para a videira e distribui-se de forma sistêmica pela planta através do sistema vascular, acarretando em baixo vigor, mesmo quando se elimina o inseto das raízes (SORIA e GALLOTTI, 1986). A penetração do estilete pode também representar um veículo para a penetração de viroses, a exemplo da transmissão, também em videiras, do Grapevine virus $B$ pela cochonilha Pseudococcus longispinus (KUNIYUKI et al., 2006).

Historicamente, a pérola da terra é uma praga de difícil controle (BOTTON et al., 2000) devido, particularmente, ao hábito subterrâneo, aliado ao desenvolvimento na forma de cisto, à dispersão e infestação facilitadas pelas formigas (NONDILLO et al., 2013). Durante a fase jovem (primeiro instar e cisto) esta espécie ataca as raízes da videira alimentando-se dos tecidos vasculares ou células de parênquima utilizando o estilete para a nutrição (FOLDI, 2005; SORIA e CONTE 2005). O inseto somente é prejudicial na fase jovem uma vez que os adultos não apresentam aparelho bucal (BOTTON et al., 2000).

As tentativas de controle têm sido restritas ao uso de inseticidas por diferentes vias de aplicação, as quais não se mostraram eficientes para evitar os danos nas videiras (BOTTON et al., 2008; BOTTON et al., 2010a; HICKEL et al., 2001; TEIXEIRA et al., 2001). Além disso, tem se procurado, no uso de agentes biológicos, uma alternativa aos inseticidas químicos (CAUSTON et al., 2004; GRAFTON-CARDWELL et al., 2005) para o controle de insetos da família Margarodidae. O díptera Prolepsis lucifer (Asilidae), um predador encontrado em populações naturais de E. brasiliensis, mostrou-se um potencial agente de controle biológico (SORIA et al., 2004) enquanto o uso de cobertura de solo com mucunapreta (Stizolobium aterrimum), não foi eficiente para o controle da pérola-da-terra (BOTTON et al., 2010b).

Considerando a importância socioeconômica derivada do impacto da pérola da terra na produção das videiras e a escassez de informações sobre a relação parasita-hospedeiro, o presente estudo visou, por meio da análise histológica, visualizar e documentar a inserção do estilete de $E$. brasiliensis nos tecidos radiciais de Vitis vinifera. 


\section{MATERIAL E MÉTODOS}

Foram coletadas aleatoriamente 250 amostras de raízes de $V$. vinifera, completamente infestadas por E. brasiliensis, provenientes de um vinhedo de Cabernet Sauvignon sobre o porta-enxerto Paulsen 1103, na Estação Experimental da Empresa de Pesquisa Agropecuária e Extensão Rural de Santa Catarina (Epagri), localizada no município de Videira, na região Centro Oeste do estado de Santa Catarina (coordenadas $27^{\circ} 01^{\prime} 28^{\prime \prime S} / 51^{\circ} 08^{\prime} 55^{\prime \prime}$, altitude $745 \mathrm{~m}$ ). Após a coleta as raízes infestadas foram fixadas em FAA70 (formol, ácido acético e álcool etílico70\%) (JOHANSEN, 1940) por 48 horas e, a seguir, armazenadas em etanol 70\%.

Para o processamento do material, segmentos da extremidade distal, com menor diâmetro, das raízes foram dispostos em porta amostras (cassetes) apropriados ao procedimento de inclusão e submetidos ao processador de tecidos da marca LUPE® onde foram submetidos a álcool absoluto e formalina (4:1) por uma hora, álcool absoluto por três horas, xilol por três horas e parafina líquida por três horas (TIMM, 2005). Os segmentos foram emblocados em parafina e permaneceram por 15 minutos no refrigerador a $-18^{\circ} \mathrm{C}$ para serem desenformados. Os blocos resultantes foram colocados por 2 horas na água amoniacal, com a finalidade de amolecer o tecido, e em seguida mantidos sob refrigeração $\left(-18^{\circ} \mathrm{C}\right)$ por aproximadamente 10 minutos, adaptando-se a técnica de Timm (2005). Foram confeccionados 62 blocos resultando em 298 lâminas seriadas.

Secções transversais e longitudinais (com relação à orientação das raízes) foram obtidas em micrótomo de rotação (Leicaß) com espessura de $4 \mu \mathrm{m}$. Os cortes foram distendidos em água a $40^{\circ} \mathrm{C}$, dispostos de forma seriada em lâminas de vidro e desparafinados em estufa a $70^{\circ} \mathrm{C}$ por um período de duas horas. A coloração foi realizada com solução aquosa de azul de toluidina 0,05\% (O'BRIEN et al. 1965), hematoxilina/eosina (JOHANSEN, 1940) e montadas em resina sintética Permount $\AA_{\text {. }}$.

As análises microscópicas e os registros fotográficos foram realizados em microscópio fotônico (Nikon®) com captura de imagem. Nas lâminas em que o estilete pode ser visualizado foi efetuada a mensuração do seu comprimento e largura através do software Motic Images Plus 2.0 (MIP-2.0). 


\section{RESULTADOS E DISCUSSÃO}

O estilete de E. brasiliensis é formado por três segmentos (Figura 1-A seta), quitinosos, originados das duas mandíbulas e da maxila que se modificam, unificando-se e formando um tubo (COSTA LIMA, 1942; FOLDI, 2005) com 6,27 $\mu \mathrm{m}$ $( \pm 0,9)$ de espessura. $O$ estilete penetra na raiz através dos tecidos da periderme $\mathrm{e}$ do córtex, ultrapassando o tecido floemático (Figura 1-C, 1-D e 1-E) e se aproximando do xilema (Figura 1-F) aprofundando-se até 650 $\mu \mathrm{m}$. Na área que circunda a inserção do estilete destaca-se a margem de coloração mais clara e aspecto irregular (Figura 1-E, 1-G e 1-H), resultado da penetração do estilete através das células, formando um "canal" e causando lise e desagregação dos componentes das paredes celulares das células atingidas. Nas células adjacentes ao canal, no entanto, não se evidenciam alterações morfológicas (Figura 1-G e 1-H). No decorrer da penetração do estilete as células adjacentes ao canal são de diferentes tipos morfológicos, periderme, córtex parenquimático (Figura 1-C e 1-D) e tecido floemático (Figura 1-E).

Kellow et al. (2004) analisando a interação entre V. vinifera e Daktulosphaira vitifoliae constataram que as células imediatamente em torno daquelas penetradas pelo estilete não apresentaram alteração perceptível em microscopia óptica, não formando um canal. Inclusive, durante a introdução do estilete de $D$. vitifoliae, diferentemente do presente estudo, não foi visualizada a penetração do mesmo no citoplasma ou no vacúolo das células (KELLOW et al., 2004). O aspecto histológico da penetração do estilete observado em E. brasiliensis é similar ao descrito por Hewer et al. (2011) e Pointeau et al. (2012) para afídeos (Hemiptera). Nos afídeos a penetração do estilete é acompanhada pela secreção de saliva que se solidifica e permanece na planta após a retirada do estilete. Esta saliva contém componentes não enzimáticos que inibem as respostas de defesa da planta com relação aos danos no sistema vascular (MILES, 1999). 
Figura 1 - Secções transversais $(A$ a $G)$ e seção longitudinal $(H)$ de raiz Vitis vinifera infestada por Eurhizococcus brasiliensis. (A) Detalhe do estilete três segmentos (seta) de $E$. brasiliensis. (B) Detalhe das células da ninfa perto do rostrum (C e D). Estilete (seta) nos tecidos da raiz. (E, F, G e H) Detalhe do estilete (seta) inserido na raiz formando um canal (estrela) por lise e rompimento das paredes das células. Ni - ninfa; Ro - células próximas à tribuna; $\mathrm{RV}$ = raiz Vitis vinifera; $\mathrm{Pe}$ - periderme, Co - córtex; Xi - xilema, CC - célula companheira (floema), ETC - elemento de tubo crivado (floema), CA - célula adjacente, Es estilete. Barra de escala: 200 um (fotomicrografias A, C e D), 30 um (fotomicrografia B), 20 um (fotomicrografias $E, F, G$ e H). Técnica de azul de toluidina (fotomicrografias $C, E, F$ e G) e técnica de hematoxilina/eosina (fotomicrografias $A, B, D$ e $H$ ).
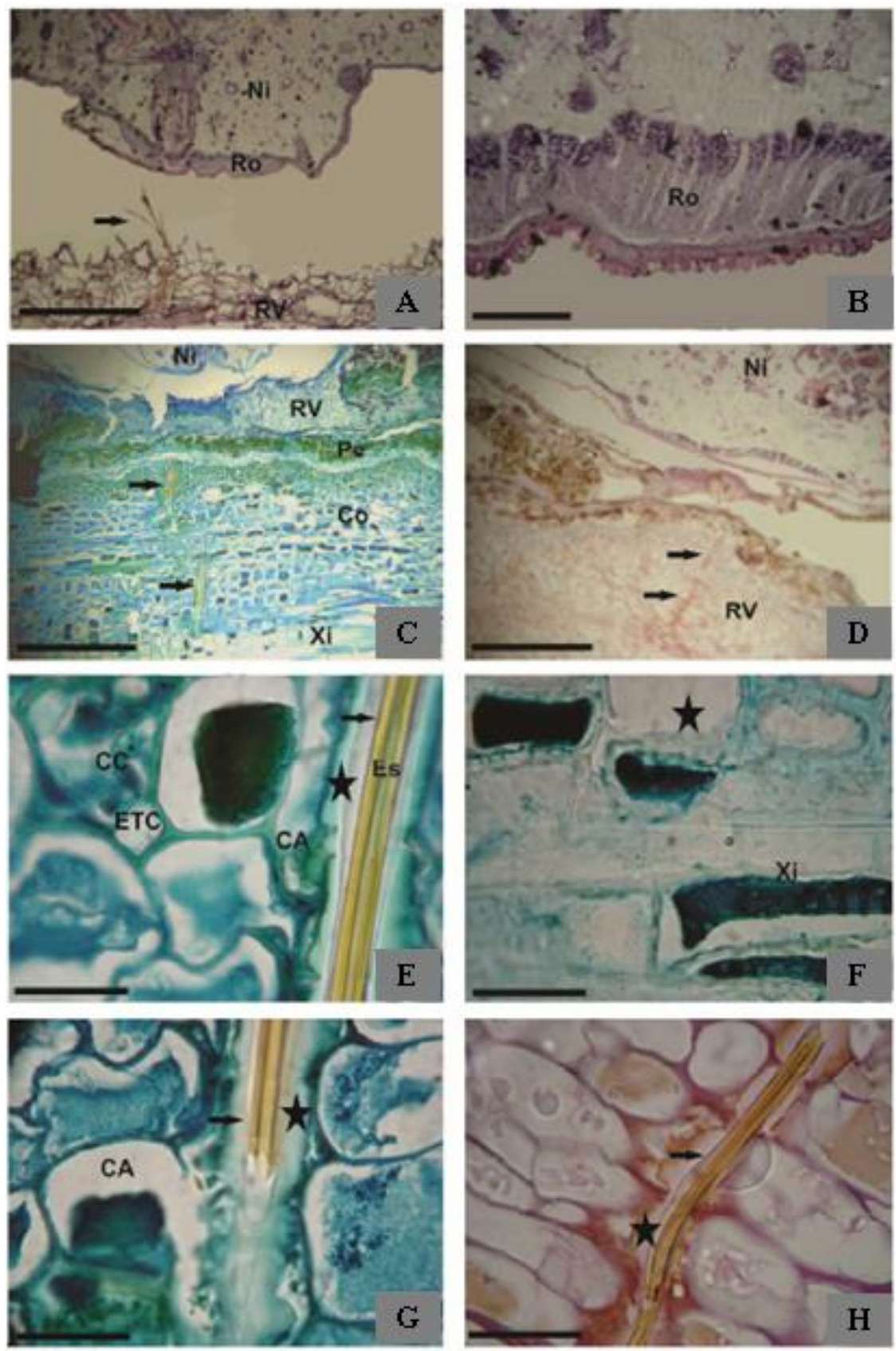


\section{CONSIDERAÇÕES FINAIS}

O presente estudo revelou detalhes dos aspectos da interação inseto-planta, permitindo visualizar a penetração do estilete nos tecidos radiciais. A análise histológica das raízes infestadas revelou que o estilete de E. brasiliensis quando introduzido na raiz de $V$. vinifera excede ao floema e aproxima-se ao xilema, causando lise e degradação dos componentes da parede celular das células atingidas.

\section{AGRADECIMENTOS}

Os autores agradecem às colaborações da médica, especialista em Anatomia Patológica, Nádia Aparecida Lorencette e do biólogo, doutor em Ciências Morfológicas, Dib Ammar.

\section{REFERÊNCIAS}

BOTTON, M., BASTOS, G., PEREIRA, O. Y ONZI, I. Efeito da cobertura vegetal sobre a pérola-da-terra (Hemiptera: Margarodidae) na cultura da videira. Acta Scientiarum. Agronomy. n.32, v.4, p.681-685, 2010a.

BOTTON, M, TEIXEIRA, I, BAVARESCO, A, PASTORI, P L. Use of soil insecticides to control the Brazilian ground pearl in vineyards. Revista Colombiana de Entomología, v. 36, p. 20-24, 2010 b.

BOTTON, M, SCHUK, E, SORIA, S DE J, HICKEL, E R. Manejo de pragas na cultura da videira. EMBRAPA Uva e Vinho, Bento Gonçalves. 2008.Disponível em: <http/www.cnpuv.embrapa.br/publica/.../perola.html.>. Acesso em: 12 nov. 2015.

BOTTON, M., HICKEL, E. R., SORIA, S. DE J. AND TEIXEIRA, I. Bioecologia e controle da pérola-da-terra Eurizococcus brasiliensis (Hempel, 1922) (Hemiptera: Margarodidae) na cultura da videira. Embrapa Uva e Vinho. Circular Técnica, 27. Bento Gonçalves: Embrapa-CNPUV, 2000. 23p.

CAUSTON, C. E.; LINCANGO M. P.; POULSOMT, G. A. Feeding range studies of Rodolia cardinalis (Mulsant), a candidate biological control agent of Icerya purchasi Maskell in the Galapagos islands. Biological Control, v.29, p.315-325, 2004.

COSTA LIMA, A. M. da. Insetos do Brasil. 3, Homópteros. Rio de Janeiro: Escola Nacional de Agronomia, 1942. p.327. 
EFROM, C.F.S.; BOTTON M.; MEYERI, G.A. Brazilian ground pearl damaging blackberry, raspberry and blueberry in Brazil. Ciência Rural, n. 42, p. 1545-1548, 2012.

FOLDI, I. Ground pearls: a generic revision of the Margarodidae sensu stricto (Hemiptera: Sternorrhyncha: Coccoidea. Annals Sociedade Entomológica, v.41, p.81-125, 2005.

GRAFTON-CARDWELL.E.E.; GU, P; MONTEZ, G.H. Effects of temperature on development of vedalia beetle, Rodolia cardinalis (Mulsant). Biological Control, v.32, p.473-478, 2005.

HEWER, A.; BECKER, A.; VAN BEL, A. J. E. An aphids Odyssey - the cortical quest for the vascular bundle. The Journal of Experimental Biology, v.214, p.38683879, 2011.

HICKEL, E.R.; PERUZZO, E.L.; SCHUCK, E. Controle da pérola-da-terra, Eurizococcus brasiliensis (Hempel, 1922) (Homoptera: Margarodidae), através da insetigação. Neotropical Entomology, v.30, p.125-132, 2001.

JOHANSEN, D.A. Plant microtechnique. New York, 1940. p.523.

KELLOW, A.V., SEDGLEY, M., VAN, H. R. Interaction Between Vitis vinifera and Grape Phylloxera: Changes in Root Tissue During Nodosity Formation. Annals of Botany, v.93, p. 581-590, 2004.

KUNIYUKI, H.; GIORIA, R.; REZENDE, J.A. M.; WILLINK, C.G; NOVO, J.C.S.; YUKI, V.E. Transmissão experimental do Grapevine virus B pela cochonilha Pseudococcus longispinus Targioni-Tozzetti (Hemiptera: Pseudococcidae). Summa Phytopathologica, v.32, p.151-155, 2006.

MELLO, L.M.R. de. Vitivinicultura Brasileira: Panorama 2012. EMBRAPA Uva e Vinho, Bento Gonçalves. 2012.

MILES, PW. Aphid saliva. Biological Review, v.74, p. 41-85, 1999.

NONDILLO, A.; SGANZERLA, V.M.A.; BUENO, O.C.; BOTTON, M. Interaction between Linepithema micans (Hymenoptera: Formicidae) and Eurhizococcus brasiliensis (Hemiptera: Margarodidae) in Vineyards. Environmental Entomology, v.42, p.460-466, 2013.

O'BRIEN, T.P., FEDER, N., MCCULLY, M.E. Polycromatic staining of plant cell walls by toluidine blue O. Protoplasma, v.59, p. 368-373, 1965.

PANIZZI, A.R.; NOAL, A.C. Eurhizococcus brasiliensis (Hempel, 1922) disseminação no município de Passo Fundo. Universidade de Passo Fundo: IPEPLAN, Passo Fundo. 1971. 34p. 
POINTEAU, S; AMELINE, A; LAURANS, F; SALLÉ, A.; RAHBÉ, Y.; BANKHEASDRONNET, S.; LIEUTIER, F. Exceptional plant penetration and feeding upon cortical parenchyma cells by the woolly poplar aphid. Journal of Insect Physiology. v.58, p.857-866, 2012.

SORIA, S.J.V.; GALLOTTI, B.J. O margarodes da videira Eurhizococcus brasiliensis (Homoptera: Margarodidae): biologia, ecologia e controle no sul do Brasil. Circular técnica 13. EMBRAPA Uva e Vinho, Bento Gonçalves. 1986.

SORIA, S. J.; MELLO R. P.; OLIVEIRA, A. M. Novos registros de Prolepsis lucifer (Wiedemann, 1928) (Diptera, Asilidae) como predador de Eurhizococcus brasiliensis (Hempel in Wille, 1922) (Hemiptera, Margarodidae) em diferentes regiões viticultoras do Rio Grande do Sul, Brasil. Entomología y Vectores v.11, p. 323-331, 2004.

SORIA, S.J., CONTE, A.F. Bioecologia e controle das pragas da videira. Circular Técnica 63. EMBRAPA Uva e Vinho, Bento Gonçalves, 2005.

TEIXEIRA, I.; MARCOS, M.; LOECK, A.E. Avaliação de inseticidas visando ao controle de Eurhizococcus brasiliensis (Hempel) (Hemiptera: Margarodidae) em novos plantios de videira. Neotropical Entomology, v.31, p.457-461, 2001.

TIMM, L.L. Técnicas Rotineiras de preparação e análise de lâminas histológicas. Caderno La Salles XI, Canoas, v.2, n.1, p.231-239, 2005.

ZART, M.; DE CÉSARO, A.; SANTOS, H.P. dos; SOUZA, P.V.D.de. Caracterização morfo-fisiológica de plantas de videira atacadas por pérola-da-terra. Semina: Ciências Agrárias, v. 35, n. 3, p. 1187-1200, 2014. 